\title{
Familial Adenomatous Polyposis
}

National Cancer Institute

\section{Source}

National Cancer Institute. Familial Adenomatous Polyposis. NCI Thesaurus. Code C3339.

An autosomal dominant disorder, characterized by the presence of multiple adenomas in the colon and rectum. It is caused by a germline mutation in the adenomatous polyposis coli (APC) gene which is located on the long arm of chromosome 5. The adenomas are most often tubular, and they have the tendency to progress to adenocarcinoma. They can occur throughout the colon, but they tend to concentrate in the rectum and sigmoid colon. The colorectal adenomas are detected during endoscopic examination between the age of 10 and 20 years. The adenomas increase in size and numbers with age, and there is usually progression of one or more adenomas to adenocarcinoma. The mean age of development of adenocarcinoma is about 40 years. Signs include rectal bleeding and mucousy diarrhea. 